\title{
Long-term Exposure to Low Concentrations of Polycyclic Aromatic Hydrocarbons and Alterations in Platelet Indices: A Longitudinal Study in China
}

\author{
Jing Cui \\ Shanxi Medical University https://orcid.org/0000-0002-3902-331X \\ Ting Zhang \\ China Institute of Radiation Protection \\ Chao Zhang \\ China Institute of Radiation Protection \\ Zhenwei Xue \\ China Institute of Radiation Protection \\ Durong Chen \\ Shanxi Medical University \\ Xiaona Kong \\ China Institute of Radiation Protection \\ Caili Zhao \\ Shanxi Medical University \\ Yufeng Guo \\ China Institute of Radiation Protection \\ Zimeng Li \\ Shanxi Medical University \\ Xiaoming Liu \\ China Institute of Radiation Protection \\ Jiefang Duan \\ Shanxi Medical University \\ Wenjie Peng \\ Shanxi Medical University \\ Xiaolin Zhou \\ China Institute of Radiation Protection \\ Hongmei Yu ( $\nabla$ yu@sxmu.edu.cn ) \\ Shanxi Medical University https://orcid.org/0000-0002-9852-2485
}

\section{Research}

Keywords: Urinary metabolites, PAHs, repeated measure, longitudinal dataset, platelet index, general linear mixed model

Posted Date: May 5th, 2021

DOI: https://doi.org/10.21203/rs.3.rs-475017/v1

License: (c) (i) This work is licensed under a Creative Commons Attribution 4.0 International License. Read Full License 


\section{Abstract}

Background High concentrations of polycyclic aromatic hydrocarbons (PAHs) can induce inflammatory and immune responses by affecting platelet indices. However, studies into low-concentration, non-occupational exposures are inconclusive in cross-sectional cohorts. We investigated low-concentration exposure to PAHs and alterations in platelet indices using a longitudinal dataset.

Methods We recruited 418 participants from Northern China between 2014 and 2017 and followed each subject for three consecutive years; 222 were included in the analysis. Demographic information was collected by questionnaire and blood and urine were sampled annually. We measured the levels of eight urinary PAH metabolites representative of exposure to PAHs. Generalised mixed models and general linear mixed models were used to estimate correlations between PAH exposure, platelet indices, and covariates.

Results We found dose-response correlations between urinary 1-hydroxynaphthalene, 2-hydroxyphenanthrene, 1-hydroxyphenanthrene, and 1-hydroxypyrene and platelet counts, as well as correlations between urinary 9-hydroxyfluorene levels and platelet distribution width, mean platelet volume, and platelet-large cell ratio. In subgroup analysis, 9-hydroxyfluorene levels were associated with mean platelet volume in participants exposed to second-hand smoke (odds ratio: $0.983 ; 95 \%$ confidence interval: $0.971-0.994$ ) and with platelet distribution width in participants who were not exposed to second-hand smoke (odds ratio: $0.955 ; 95 \%$ confidence interval: 0.913-0.999).

Conclusions Long-term exposure to low concentrations of PAHs affects platelet count, platelet distribution width, mean platelet volume, and platelet-large cell ratio, and the effects may be modified by exposure to second-hand smoke.

\section{Introduction}

Polycyclic aromatic hydrocarbons (PAHs) are air pollutants with at least two fused aromatic rings that vary in origin. Outdoors, PAHs are formed by incomplete combustion of coal, petroleum, wood, tobacco, and organic macromolecular compounds [1]. Indoors, PAHs are formed from smoking and carbonbaked foods [2]. The acute effects of PAHs on human health depend on the concentration, duration, and route of exposure. Multiple studies have focused on occupational and high-concentration exposures, which can exert adverse effects on nasal tissues, red blood cells, platelets, and white blood cells or the uterus, hair follicles, brain, spleen, placenta, liver, lungs, and kidneys [3]. Chronic effects may include immunotoxicity, cytotoxicity [4-6], immune dysfunction [4, 7], dyslipidaemia [8], asthma [9], fetal dysplasia [5], and cardiovascular disease [10]. For example, high-dose exposure to vehicular combustion products has been reported to increase platelet counts [11] and exert other effects on platelet activity [12,13]. In rabbits, high-dose exposure to PAHs was shown to affect the synthesis of thromboxane B2.

Long exposure to low concentrations may cause low-grade inflammation [4] owing to alterations in platelet indices [14]. Chronic exposure to low concentrations of PAHs has also been estimated from cross-sectional datasets [15], but such a design may not reflect the effects of PAHs on white blood cells accurately, leading to conflicting results [16] [17]. Hence, longitudinal datasets may be more appropriate for studying the effects of long-term exposure to low concentrations of PAHs on platelet indices among adults who are not occupationally exposed.

Risk assessment in environmental pollution relies on dose-response relationships [3], and biomarkers have been suggested as reliable tools in epidemiology. The breakdown products of PAHs are excreted mostly through urine $[1,5,10,18]$. However, as the effects of individual mixture constituents is unknown, we studied eight representative urinary PAH metabolites and estimated their correlations with five platelet indices and the effect of covariates. We used a longitudinal dataset to assess whether low-concentration exposure to PAHs affects platelet indices.

\section{Materials And Methods}

\subsection{Study population}

A total of 418 participants from Northern China [19] were enrolled by the China Institute for Radiation Protection between 2014 and 2019. All participants had resided for more than 25 years in a village located downwind and 1-2 km from a coal plant but were not employed by the plant or related businesses. As these residences are near each other in the village, participant exposure to automobile exhaust was not considered. During the three waves of follow-up in June (non-heating season) of 2015, 2016, and 2017, demographic information was collected by questionnaire through in-person interviews conducted by rigorously trained interviewers. Urine and blood samples were collected in the same morning at each of the three follow-up points. Complete records were available for 222 subjects (Fig. 1).

Participants were grouped by their year of enrolment: 63 participants in 2014, 69 in 2015, 51 in 2016, and 39 in 2017 . All subjects provided informed consent for participation and for the storage and use of their blood and urine samples. The China Institute for Radiation Protection approved the research, complying with subject confidentiality and informed consent was obtained from all study participants.

\subsection{Measurement of urinary metabolites}

Morning urine samples were collected from each participant in clean polypropylene tubes in June of three consecutive annual follow-ups. All urine samples were stored at $-20^{\circ} \mathrm{C}$ until use. The limits of detection of PAHs ranged from 0.1 to $0.9 \mu \mathrm{g} / \mathrm{L}$ and default values were replaced by $50 \%$ of the limit of detection. We tested for eight PAHs: 1-hydroxynaphthalene, 2-hydroxynaphthalene, 2-hydroxyfluorene, 9-hydroxyfluorene, 2-hydroxyphenanthrene, 1-

hydroxyphenanthrene, 1-hydroxypyrene, and 3-hydroxybenzo[a]pyrene. The testing process has been described previously [20]. Briefly, urine samples were hydrolysed with $\beta$-glucuronidase/sulfatase (Roche, Basel, Switzerland) and purified with $\mathrm{C} 18$ cartridges (surface area: $525 \mathrm{~m}^{2} / \mathrm{g}$ per cartridge; average particle size: $52.1 \mu \mathrm{m}$, Supelco, Inc., Bellefonte, PA, USA). Next, a 400- $\mu \mathrm{L}$ extract was produced by condensation under nitrogen gas. We then used high-performance 
liquid chromatography (Waters 2695, Milford, MA, USA) with a fluorescence detector for analysis. The linearity (expressed as the R value), mean relative standard deviation, and mean recovery rate of samples were $0.999-1.0000 \%, 0.70-8.36 \%$, and $81.83-123.75 \%$, respectively.

\subsection{Measurement of platelet indices}

Samples $(15 \mathrm{~mL})$ of fasting blood were collected from each patient using standard methods [21] and analysed for leukocyte, erythrocyte, thrombocyte, and immunoglobulin indices with a Hemaray 86 automatic hematological analyser (Rayto Co., Shen Zhen, China). Five platelet indices were measured: platelet count, platelet distribution width, mean platelet volume, plateletcrit, and platelet-large cell ratio.

\subsection{Covariates}

The following variables were used as covariates: age, sex, weight, and height. Body mass index was calculated as weight divided by height and was categorised as $<18.5 \mathrm{~kg} / \mathrm{m}^{2}, 18.5-28 \mathrm{~kg} / \mathrm{m}^{2}$, and $>28 \mathrm{~kg} / \mathrm{m}^{2}$. Participants were also grouped by age ( $\leq 60$ and $>60$ years). Habitual smokers were defined as those smoking at least one cigarette per day for at least 6 months [22]. Second-hand smoke exposure was defined as residing with an adult who smoked more than one pack per week. Alcohol consumption was defined as a history of consuming alcohol for more than 1 year. Considering that high-frequency intake of barbecued foods increases PAH exposure [23] and that barbecue was not the main cooking method in this village, the 11 participants who reported barbecuing foods were excluded from the analysis.

\subsection{Statistical analyses}

We first used univariate statistical inference for demographic characteristics and urinary PAH metabolite levels and their changes between sampling points. We used the Shapiro-Wilk test to assess normality and analysis of variance, least significant difference, Chi-squared, Wilcoxon rank sum, and Kruskal-Wallis $\mathrm{H}$ tests to identify differences between groups. Next, we used Spearman's correlation analysis and K-means cluster methods to determine whether the demographic information correlated with mean changes in urinary PAH metabolites. To identify changes in thrombocyte indices and urinary PAH metabolites over time, we used multivariate analysis of variance for repeated measurements [24] and traditional analysis of variance for variables that met and did not meet sphericity, respectively. We then used general mixed models [25] to evaluate correlations between urinary PAH metabolite levels and thrombocyte indices After excluding the indices without statistical significance, we constructed general linear mixed models [26] to determine whether the correlations had a linear distribution. To further estimate the effect of PAHs on thrombocyte indices, we constructed three adjusted models. Model 1 was a time model where "group" was the main effect and we adjusted for time. Model 2 adjusted for time, age, sex, and body mass index. Model 3 adjusted for the variables in Model 2 plus smoking status, exposure to second-hand smoke, and alcohol consumption. We also estimated the Akaike information criterion (AIC) [27] and Bayesian information criterion (BIC) [28] for model assessment. The AIC forms the penalised likelihood into a negative log-likelihood plus a penalty term in Eq. 1, in which the $\mathrm{k}$ stands for the number of free parameters. The BIC exerts a higher penalty than the AIC in model overfitting (Eq. 2). As long as the true model is one of the candidate models, the model with the minimum BIC exhibits the best performance. If the true model is not one of the candidate models, the model with the minimum AIC exhibits the best performance [29].

$$
\begin{aligned}
& \text { AIC }=-2 \log \mathrm{L}(\hat{\theta})+2 \mathrm{k} \\
& \mathrm{BIC}=-2 \log \mathrm{L}(\hat{\theta})+\ln (\mathrm{k})
\end{aligned}
$$

All data were double-entered into EpiData 3.0 with a consistency of $99.9 \%$ and all models were fitted by SAS 9.4 . More details on model fit are given in the Supplementary Materials.

\section{Results}

\subsection{Characteristics of study participants}

Participant age ranged from 55 to 65 years and did not vary by year of recruitment into the study $(2014,2015,2016$, or 2017). Slightly more than half of participants were women. More than half of the participants (56\%) were overweight, without a specific difference between groups. Changes in urinary metabolite levels between sampling points did not differ by year of recruitment into the study (Table 1). 
Table 1

Basic information of 222 participants

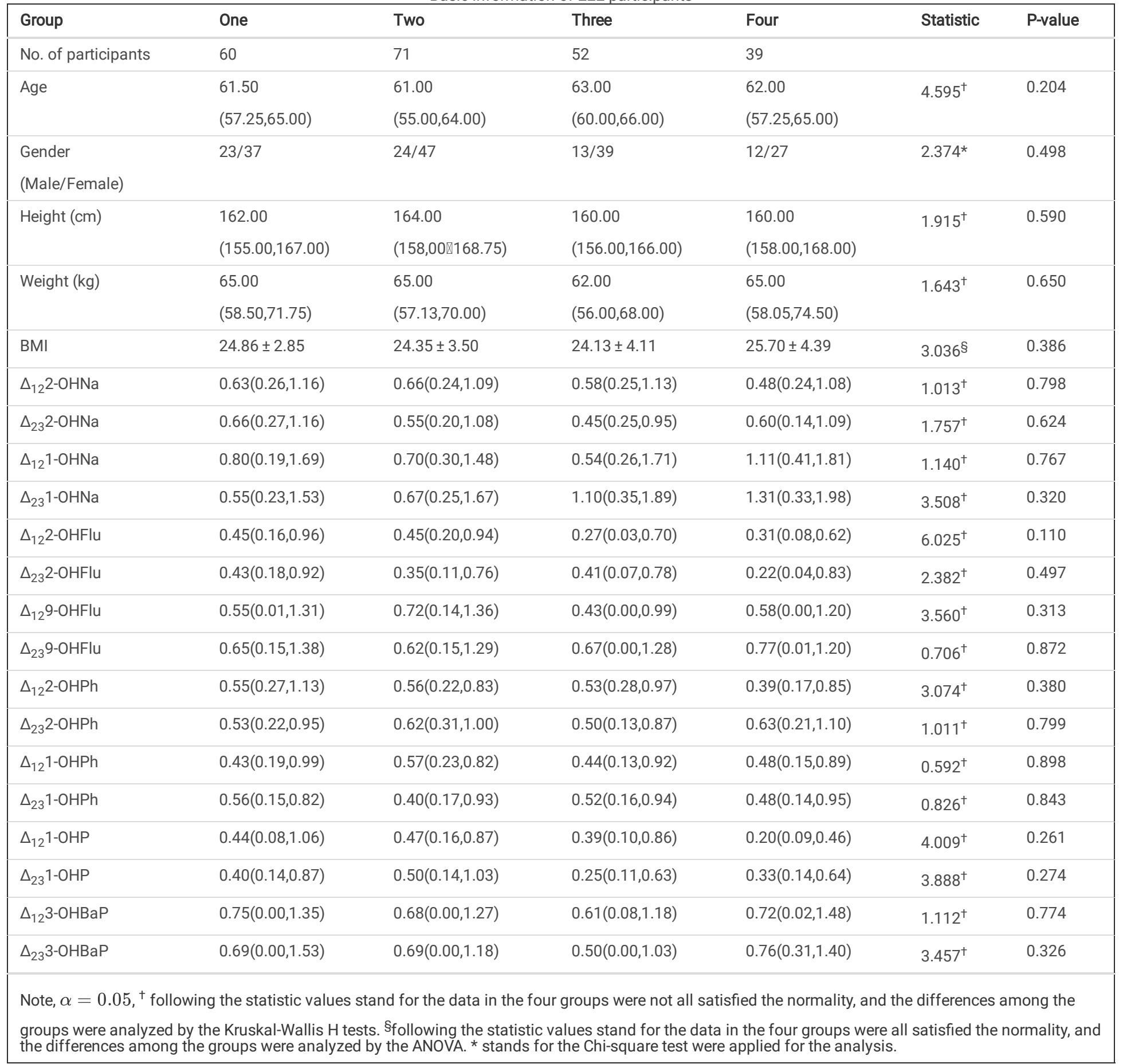

\subsection{Correlations between demographic information and urinary metabolite levels}

Spearman correlation coefficients for the relationship between urinary PAH metabolite levels and platelet indices differed from the null hypothesis $(P<0.05)$ but were very small; the highest coefficient was 0.15 , calculated for the relationship between the levels of 2-hydroxyfluorene and platelet distribution width. Second-hand smoke exposure and age clustered with three urinary PAH metabolites (1-hydroxynaphthalene, 9-hydroxyfluorene, and 33-hydroxybenzo[a]pyrene; Fig. 2). Although their correlations lacked statistical significance, we included age and second-hand smoke exposure as covariates in further model fitting.

Figure Notes of Fig. 2, "matesmoke" stands for the second-hand smoke exposure. "smoke" stands for the active smoke.

\subsection{Variations in urinary metabolite levels over time}

We analysed variations over time in urinary PAH metabolite levels and platelet indices. To eliminate the effect of recruitment year, we first grouped participant data by the year of recruitment into the study. All participants were healthy and we did not find changes in platelet indices between consecutive years. The levels urinary PAH metabolites were log-transformed before testing so some of the means were negative values. The levels of five urinary PAH metabolites measured over three years varied in participant groups recruited in 2014 and 2015. The levels of 2-hydroxynaphthalene and 1-hydroxyphenanthrene varied 
over time in groups recruited in 2014 and 2015. Levels of 2-hydroxyphenanthrene varied in the 2014 group, and levels of 2-hydroxyfluorene and 1hydroxypyrene varied in the 2015 group.

Table.2 The variates of platelet indices and UPAHM among times

\begin{tabular}{|c|c|c|c|c|c|c|c|c|c|c|c|}
\hline Group & Var & PLT & PDW & MPV & РCT & PLCR & $2-\mathrm{OHNa}$ & $1-\mathrm{OHNa}$ & 9-OHFlu & 2-OHFlu & 2-OHPh \\
\hline \multirow[t]{5}{*}{ One } & 1 & $\begin{array}{l}223.24 \pm \\
87.00\end{array}$ & $\begin{array}{l}11.21 \pm \\
3.34\end{array}$ & $\begin{array}{l}9.53 \pm \\
2.35\end{array}$ & $\begin{array}{l}0.23 \pm \\
0.08\end{array}$ & $\begin{array}{l}23.68 \pm \\
9.05\end{array}$ & $0.62 \pm 0.86$ & $\begin{array}{l}0.92 \pm \\
0.93\end{array}$ & $\begin{array}{l}0.97 \pm \\
0.85\end{array}$ & $0.28 \pm 0.64$ & $\begin{array}{l}-0.13 \pm \\
0.70\end{array}$ \\
\hline & 2 & $\begin{array}{l}203.98 \pm \\
88.71\end{array}$ & $\begin{array}{l}10.48 \pm \\
3.83\end{array}$ & $\begin{array}{l}8.99 \pm \\
3.07\end{array}$ & $\begin{array}{l}0.21 \pm \\
0.09\end{array}$ & $\begin{array}{l}24.84 \pm \\
24.71\end{array}$ & $0.39 \pm 0.81$ & $\begin{array}{l}0.77 \pm \\
0.90\end{array}$ & $\begin{array}{l}0.89 \pm \\
0.79\end{array}$ & $0.10 \pm 0.65$ & $\begin{array}{l}-0.24 \pm \\
0.68\end{array}$ \\
\hline & 3 & $\begin{array}{l}241.14 \pm \\
88.54\end{array}$ & $\begin{array}{l}11.02 \pm \\
3.42\end{array}$ & $\begin{array}{l}9.38 \pm \\
2.61\end{array}$ & $\begin{array}{l}0.23 \pm \\
0.08\end{array}$ & $\begin{array}{l}23.14 \pm \\
9.19\end{array}$ & $0.31 \pm 0.74$ & $\begin{array}{l}0.94 \pm \\
0.90\end{array}$ & $\begin{array}{l}1.06 \pm \\
0.81\end{array}$ & $0.20 \pm 0.75$ & $\begin{array}{l}-0.20 \pm \\
0.75\end{array}$ \\
\hline & ST & 0.6383 & 0.0141 & 0.0001 & 0.2596 & $<0.0001$ & 0.115 & 0.5949 & 0.8968 & 0.0164 & 0.0435 \\
\hline & $\begin{array}{l}F \\
(p)\end{array}$ & $2.58(0.08)$ & $0.82(0.42)$ & $0.84(0.40)$ & $0.55(0.57)$ & $0.19(0.73)$ & $2.27(0.11)$ & $0.84(0.43)$ & $0.57(0.56)$ & $1.20(0.31)$ & $0.47(0.61)$ \\
\hline \multirow[t]{5}{*}{ Two } & 1 & $\begin{array}{l}215.84 \pm \\
84.97\end{array}$ & $\begin{array}{l}10.54 \pm \\
3.15\end{array}$ & $\begin{array}{l}9.22 \pm \\
2.46\end{array}$ & $\begin{array}{l}0.23 \pm \\
0.08\end{array}$ & $\begin{array}{l}24.38 \pm \\
23.30\end{array}$ & $0.53 \pm 0.77$ & $\begin{array}{l}0.65 \pm \\
0.86\end{array}$ & $\begin{array}{l}0.88 \pm \\
0.83\end{array}$ & $0.16 \pm 0.60$ & $\begin{array}{l}-0.20 \pm \\
0.68\end{array}$ \\
\hline & 2 & $\begin{array}{l}234.88 \pm \\
73.54\end{array}$ & $\begin{array}{l}11.32 \pm \\
3.17\end{array}$ & $\begin{array}{l}9.57 \pm \\
2.27\end{array}$ & $\begin{array}{l}0.23 \pm \\
0.07\end{array}$ & $\begin{array}{l}23.62 \pm \\
9.02\end{array}$ & $0.27 \pm 0.71$ & $\begin{array}{l}0.74 \pm \\
0.88\end{array}$ & $\begin{array}{l}0.97 \pm \\
0.81\end{array}$ & $0.10 \pm 0.74$ & $\begin{array}{l}-0.20 \pm \\
0.71\end{array}$ \\
\hline & 3 & $\begin{array}{l}229.67 \pm \\
77.51\end{array}$ & $\begin{array}{l}11.32 \pm \\
2.61\end{array}$ & $\begin{array}{l}9.67 \pm \\
1.89\end{array}$ & $\begin{array}{l}0.23 \pm \\
0.07\end{array}$ & $\begin{array}{l}24.03 \pm \\
7.84\end{array}$ & $0.57 \pm 0.71$ & $\begin{array}{l}0.91 \pm \\
0.95\end{array}$ & $\begin{array}{l}0.78 \pm \\
0.71\end{array}$ & $0.29 \pm 0.62$ & $0.05 \pm 0.55$ \\
\hline & ST & 0.264 & 0.2286 & 0.1744 & 0.3933 & $<0.0001$ & 0.3599 & 0.9649 & 0.1981 & 0.282 & 0.0976 \\
\hline & $\begin{array}{l}F \\
(p)\end{array}$ & $0.85(0.43)$ & $1.35(0.27)$ & $0.73(0.49)$ & $0.20(0.82)$ & $0.04(0.89)$ & $4.85(0.01)^{*}$ & $1.46(0.24)$ & $1.25(0.29)$ & $1.53(0.22)$ & $3.50(0.04)^{\star}$ \\
\hline \multirow[t]{5}{*}{ Three } & 1 & $\begin{array}{l}221.96 \pm \\
70.17\end{array}$ & $\begin{array}{l}11.09 \pm \\
2.00\end{array}$ & $\begin{array}{l}9.64 \pm \\
1.54\end{array}$ & $\begin{array}{l}0.23 \pm \\
0.06\end{array}$ & $\begin{array}{l}23.23 \pm \\
6.11\end{array}$ & $0.30 \pm 0.79$ & $\begin{array}{l}0.86 \pm \\
0.94\end{array}$ & $\begin{array}{l}0.98 \pm \\
0.81\end{array}$ & $0.10 \pm 0.69$ & $\begin{array}{l}-0.16 \pm \\
0.69\end{array}$ \\
\hline & 2 & $\begin{array}{l}225.27 \pm \\
88.76\end{array}$ & $\begin{array}{l}10.70 \pm \\
3.03\end{array}$ & $\begin{array}{l}9.31 \pm \\
2.47\end{array}$ & $\begin{array}{l}0.21 \pm \\
0.08\end{array}$ & $\begin{array}{l}22.65 \pm \\
8.07\end{array}$ & $0.60 \pm 0.66$ & $\begin{array}{l}1.13 \pm \\
0.92\end{array}$ & $\begin{array}{l}0.91 \pm \\
0.75\end{array}$ & $0.39 \pm 0.59$ & $0.08 \pm 0.60$ \\
\hline & 3 & $\begin{array}{l}232.65 \pm \\
96.28\end{array}$ & $\begin{array}{l}10.27 \pm \\
3.12\end{array}$ & $\begin{array}{l}8.97 \pm \\
2.73\end{array}$ & $\begin{array}{l}0.22 \pm \\
0.09\end{array}$ & $\begin{array}{l}20.96 \pm \\
7.87\end{array}$ & $0.66 \pm 0.66$ & $\begin{array}{l}1.02 \pm \\
1.09\end{array}$ & $\begin{array}{l}0.84 \pm \\
0.76\end{array}$ & $0.42 \pm 0.58$ & $0.09 \pm 0.63$ \\
\hline & ST & 0.3735 & 0.0078 & 0.003 & 0.1172 & 0.5347 & 0.7573 & 0.5221 & 0.6228 & 0.4274 & 0.4299 \\
\hline & $\begin{array}{l}F \\
(p)\end{array}$ & $0.24(0.79)$ & $1.31(0.27)$ & $1.51(0.23)$ & $0.67(0.51)$ & $1.50(0.23)$ & $4.27(0.02)^{*}$ & $1.34(0.27)$ & $0.52(0.60)$ & $4.61(0.01)^{*}$ & $2.97(0.06)$ \\
\hline \multirow[t]{5}{*}{ Four } & 1 & $\begin{array}{l}231.85 \pm \\
85.87\end{array}$ & $\begin{array}{l}10.59 \pm \\
3.51\end{array}$ & $\begin{array}{l}9.14 \pm \\
2.82\end{array}$ & $\begin{array}{l}0.22 \pm \\
0.08\end{array}$ & $\begin{array}{l}22.16 \pm \\
9.16\end{array}$ & $0.57 \pm 0.86$ & $\begin{array}{l}0.92 \pm \\
0.90\end{array}$ & $\begin{array}{l}0.68 \pm \\
0.74\end{array}$ & $0.34 \pm 0.64$ & $\begin{array}{l}-0.07 \pm \\
0.70\end{array}$ \\
\hline & 2 & $\begin{array}{l}212.74 \pm \\
100.36\end{array}$ & $\begin{array}{l}9.73 \pm \\
3.72\end{array}$ & $\begin{array}{l}8.68 \pm \\
3.09\end{array}$ & $\begin{array}{l}0.21 \pm \\
0.10\end{array}$ & $\begin{array}{l}19.81 \pm \\
9.16\end{array}$ & $0.53 \pm 0.63$ & $\begin{array}{l}0.94 \pm \\
1.04\end{array}$ & $\begin{array}{l}0.81 \pm \\
0.79\end{array}$ & $0.30 \pm 0.50$ & $\begin{array}{l}-0.03 \pm \\
0.56\end{array}$ \\
\hline & 3 & $\begin{array}{l}236.33 \pm \\
102.31\end{array}$ & $\begin{array}{l}10.06 \pm \\
3.73\end{array}$ & $\begin{array}{l}8.83 \pm \\
3.11\end{array}$ & $\begin{array}{l}0.22 \pm \\
0.09\end{array}$ & $\begin{array}{l}20.85 \pm \\
9.01\end{array}$ & $0.40 \pm 0.76$ & $\begin{array}{l}0.90 \pm \\
1.00\end{array}$ & $\begin{array}{l}0.82 \pm \\
0.75\end{array}$ & $0.27 \pm 0.69$ & $\begin{array}{l}-0.00 \pm \\
0.77\end{array}$ \\
\hline & ST & 0.7258 & 0.4317 & 0.3941 & 0.2224 & 0.1377 & 0.3417 & 0.3222 & 0.8852 & 0.2258 & 0.192 \\
\hline & $\begin{array}{l}F \\
(p)\end{array}$ & $0.92(0.41)$ & $1.19(0.32)$ & $0.57(0.57)$ & $0.29(0.74)$ & $1.48(0.24)$ & $0.64(0.53)$ & $0.02(0.98)$ & $0.46(0.63)$ & $0.09(0.91)$ & $0.10(0.90)$ \\
\hline
\end{tabular}

Note, we classed the participants into four groups according to their years of participation, and Group one includes the one who participated in 2014 , while pe in Group two to four, respectively. They were all emendating with Creatinine. Listing the geometric mean \pm geometric standard error for each following-up tim $\epsilon$ Mauchly's test of sphericity have been listed in the fourth row of each group with "ST" for short. The last row of each group listed the results of ANOVA for re, traditional ANOVA analysis while their $\mathrm{P}$ values have been displayed in the brackets after $\mathrm{F}$ values. * stands for the statistical significance with $\mathrm{a}=0.05$.

\subsection{Correlations between urinary metabolite levels and platelet indices}

To assess the effect of PAH exposure on platelet indices, we fitted general mixed models to the data to estimate fixed effects. Eight correlations were statistically significant: the correlations between 1-hydroxynaphthalene, 2-hydroxyfluorene, 2-hydroxyphenanthrene, 1-hydroxyphenanthrene, and 1hydroxypyrene and platelet count and the correlations between 9-hydroxyfluorene and platelet distribution width, mean platelet volume, and platelet-large cell ratio (Table 3). Supplementary Table S1 lists the random effects of the general mixed models. 
Table 3

The fixed effect among platelet indices and UPAHM based on GMMs

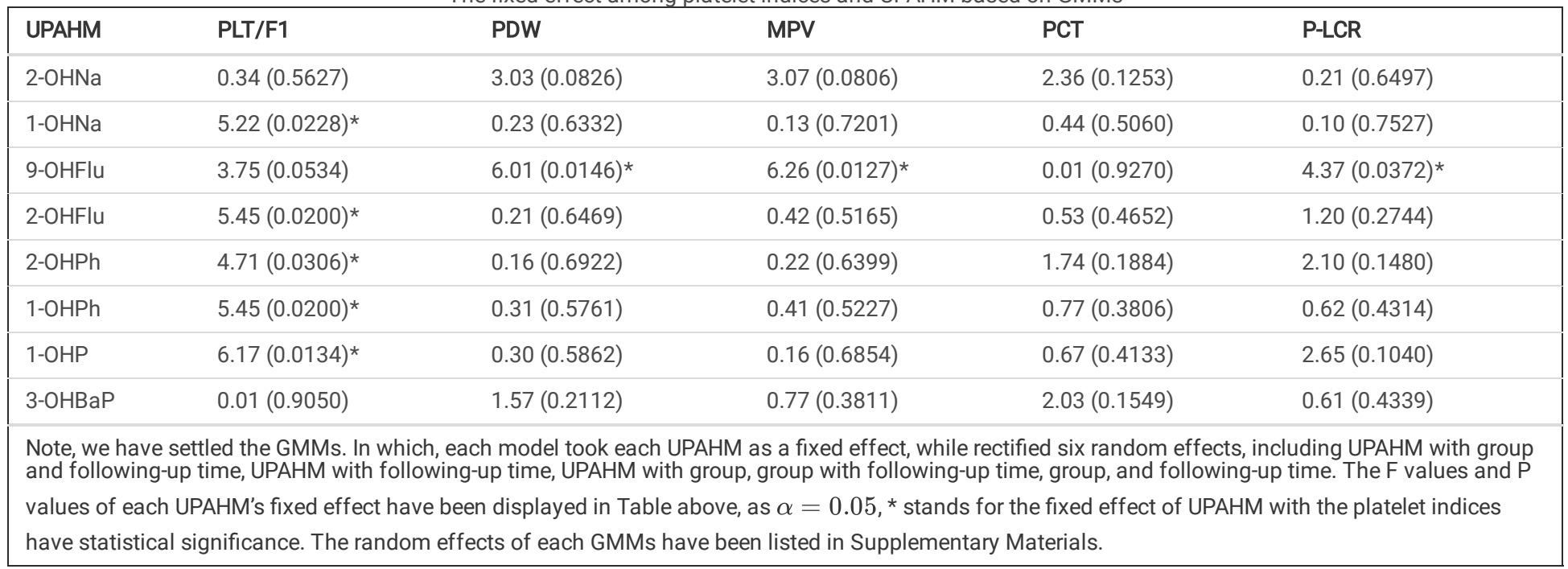

\subsection{Dose-response associations between exposure and platelet indices}

We fitted three general linear mixed models using the eight correlations for dose-response analysis using various covariates. We then categorised urinary PAH metabolite levels into four groups and estimated how these exposure levels would affect platelet indices. We found a linear relationship between the levels of 1-hydroxynaphthalene, 2-hydroxyphenanthrene, 1-hydroxyphenanthrene, and 1-hydroxypyrene and platelet counts (Table 4). According to the AIC and BIC, Model 3, containing the largest number of covariates, performed best. Supplementary Table S2 lists the odds ratios and $95 \%$ confidence intervals for the covariates. 
Table 4

Dose-reposed effect of PAH exposure on PLT/F1

\begin{tabular}{|c|c|c|c|}
\hline Level of UPAHM & Model 1 & Model 2 & Model 3 \\
\hline \multicolumn{4}{|l|}{$1-\mathrm{OHNa}$} \\
\hline 1.00 & $0.95(0.916-0.986)^{*}$ & $0.951(0.916-0.987)^{\star}$ & $0.95(0.916-0.986)^{*}$ \\
\hline 2.00 & $0.945(0.9-0.993) *$ & $0.946(0.9-0.993) \star$ & $0.943(0.897-0.991)^{\star}$ \\
\hline 3.00 & $0.962(0.924-1.001)$ & $0.962(0.924-1.002)$ & $0.961(0.923-1.001)$ \\
\hline 4.00 & 1 & 1 & 1 \\
\hline AIC & -286.9 & -268.9 & -251 \\
\hline $\mathrm{BIC}$ & -266.5 & -248.5 & -230.6 \\
\hline \multicolumn{4}{|l|}{ 2-OHFlu } \\
\hline 1.00 & $0.966(0.928-1.005)$ & $0.966(0.928-1.006)$ & $0.967(0.928-1.007)$ \\
\hline 2.00 & $0.961(0.923-1)$ & $0.961(0.922-1)$ & $0.961(0.923-1.001)$ \\
\hline 3.00 & $1.008(0.969-1.049)$ & $1.007(0.967-1.049)$ & $1.007(0.967-1.049)$ \\
\hline 4.00 & 1 & 1 & 1 \\
\hline AIC & -286.2 & -268.2 & -249.6 \\
\hline BIC & -265.8 & -247.8 & -229.2 \\
\hline \multicolumn{4}{|l|}{ 2-OHPh } \\
\hline 1.00 & $0.941(0.904-0.979)^{\star}$ & $0.941(0.904-0.98)^{\star}$ & $0.941(0.904-0.98)^{\star}$ \\
\hline 2.00 & $0.939(0.904-0.976)^{\star}$ & $0.939(0.904-0.977)^{\star}$ & $0.94(0.904-0.977)^{*}$ \\
\hline 3.00 & $0.951(0.912-0.991)^{\star}$ & $0.95(0.911-0.99)^{\star}$ & $0.949(0.91-0.99)^{\star}$ \\
\hline 4.00 & 1 & 1 & 1 \\
\hline AIC & -290.1 & -272.2 & -253.8 \\
\hline $\mathrm{BIC}$ & -269.7 & -251.8 & -233.4 \\
\hline \multicolumn{4}{|l|}{ 1-OHPh } \\
\hline 1.00 & $0.958(0.92-0.997)^{*}$ & $0.958(0.92-0.997)^{\star}$ & $0.957(0.919-0.996)^{\star}$ \\
\hline 2.00 & $0.958(0.924-0.993)^{\star}$ & $0.958(0.924-0.994) *$ & $0.958(0.924-0.994)^{\star}$ \\
\hline 3.00 & $0.992(0.944-1.042)$ & $0.991(0.943-1.041)$ & $0.99(0.942-1.04)$ \\
\hline 4.00 & 1 & 1 & 1 \\
\hline AIC & -285.4 & -267.5 & -249.2 \\
\hline $\mathrm{BIC}$ & -265 & -247.1 & -228.8 \\
\hline \multicolumn{4}{|l|}{ 1-OHP } \\
\hline 1.00 & $0.948(0.902-0.996)^{\star}$ & $0.949(0.903-0.997)$ * & $0.949(0.903-0.997)^{\star}$ \\
\hline 2.00 & $0.99(0.942-1.04)$ & $0.992(0.944-1.043)$ & $0.992(0.944-1.043)$ \\
\hline 3.00 & $0.988(0.942-1.035)$ & $0.989(0.944-1.037)$ & $0.99(0.944-1.038)$ \\
\hline 4.00 & 1 & 1 & 1 \\
\hline AIC & -285.4 & -267.8 & -249.4 \\
\hline BIC & -265 & -247.3 & -228.9 \\
\hline \multicolumn{4}{|c|}{$\begin{array}{l}\text { Notes, by adding different covariants, three general linear models were settled for the dose-respond effect of the PAH exposure and the PLT/F1. The group } \\
\text { and time were adjusted in Model } 1 \text {, while Model } 2 \text { added extra three demographic informations on the base of Model } 1 \text {, including age, gender, and BMI. } \\
\text { Besides, Model } 3 \text { added more habitual variables based on Model } 2 \text {, including smoke, drink, and passive smoke. The Odd ratio(OR) and their } 95 \% \\
\text { confidence intervals were listed in the above Table. * stands for the UPAHM level were different from the reference level with statistical significance and a } \\
=0.05 \text {. AIC and BIC for each model were listed after the levels. }\end{array}$} \\
\hline
\end{tabular}

9-Hydroxyfluorene levels were correlated with platelet distribution width, mean platelet volume, and platelet-large cell ratio and we found an association with exposure to second-hand smoke. Subgroup analysis by exposure to second-hand smoke (yes/no) was conducted using Model 1 to determine whether the correlations observed between 9-hydroxyfluorene levels and platelet indices were true or confounded by exposure to second-hand smoke (Fig. 3). For platelet distribution width, only participants who were not exposed to second-hand smoke exhibited the dose-response trend of the entire cohort, in which the first 
exposure level differed from the highest effect (odds ratio without exposure to second-hand smoke: 0.955; 95\% confidence interval: 0.913-0.999). For mean platelet volume, only participants who were exposed to second-hand smoke exhibited the dose-response trend of the entire cohort, in which the first exposure level differed from the highest effect (odds ratio with exposure to second-hand smoke: $0.983 ; 95 \%$ confidence interval: $0.971-0.994)$. As the odds ratio in the entire participant cohort was estimated at 0.944 (0.911-0.980), the group of participants exposed to second-hand smoke had a larger odds ratio and narrower confidence interval. For platelet-large cell ratio, subgroups did not differ (Fig. 3). Supplementary Table S3 lists details of the analysis and general linear mixed models.

Figure Notes of Fig. 3, the forest plot for subgroup analysis. In which, the "matesmoke = 1" stands for the group without the second-hand smoke exposure, and the "matesmoke = 2" stands for the group with the second-hand smoke exposure. "All" stands for the model settled without adjustment of passive smoke.

\section{Discussion}

We used a longitudinal dataset to estimate the effects of exposure to low concentrations of PAHs on platelet indices using urinary PAH metabolites as biomarkers of exposure. Five metabolites were associated with platelet counts: 2-hydroxyfluorene, 1-hydroxynaphthalene, 2-hydroxyphenanthrene, 1hydroxyphenanthrene, and 1-hydroxypyrene; all except 2-hydroxyfluorene exhibited dose-response relationships with linear correlations. Additionally, urinary levels of 9-hydroxyfluorene were linearly correlated with platelet distribution width, mean platelet volume, and platelet-large cell ratio, and that exposure to second-hand smoke was also a factor. Subgroup analysis showed that second-hand smoke exposure may bias the correlations between 9-hydroxyfluorene levels and platelet indices: 9-hydroxyfluorene appeared to affect mean platelet volume in participants exposed to second-hand smoke and platelet distribution width in participants who were not.

Platelets contribute to haemostasis and coagulation, and have been proposed as blood biomarkers in studies of inflammation and immune responses [30]. Mean platelet volume and platelet distribution width have been associated with coronary artery diseases, as they may reflect the size and activity of platelets in thrombosis [31] and inflammation [32,33]. The induction of thromboxane A2 aggregates platelets to a site of inflammation [34]. Changes in mean platelet volume have been associated with hypertrophic cardiomyopathy [35], pulmonary hypertension [36], restenosis following coronary angioplasty, acute myocardial infarction [31], Wiskott-Aldrich syndrome [37], and giant platelet disorders [38]. Platelet distribution width has been suggested as an important clinical factor of pulmonary arterial hypertension [39] and dementia [40]. identifying changes in these platelet indices and understanding their pathogenesis is of clinical relevance.

Both epidemiological and animal experiments have shown that PAH exposure can induce inflammatory responses [41-43] and alter platelet indices [15, 44]. PAH monohydroxy intermediates are generated through redox-active cycling with cytochrome P450 enzymes and quinone oxidoreductase [15] and can affect cells and tissues [45] and react with DNA and proteins to trigger the generation of reactive oxygen species and expression of pro-inflammatory genes [46]. Twenty four or $48 \mathrm{~h}$ after exposure to PAHs, increases in the pro-inflammatory cytokines interleukin 1b, 8, 12, and 10 have been reported in THP-1 macrophagelike cells [47], and positive associations have been noted in humans between urinary PAH metabolite levels and markers of inflammation [48]. We measured the levels of eight urinary PAH metabolites as biomarkers of exposure to avoid the uncertainty of single biomarkers [49]. Effects on platelet counts have been recorded for PAHs generated during residential and professional cooking [50]. Our findings suggest that PAH exposure (in particular PAHs that metabolize to 9hydroxyfluorene) affects mean platelet volume, platelet distribution width, and platelet-large cell ratio.

Exposure to second-hand smoke modified some of the associations. Cao and colleagues reported that urinary levels of 1-hydroxynaphthalene, 2hydroxynaphthalene, and 2-hydroxyfluorene correlated with smoking [2]. To our knowledge, ours is the first study to report an association between cigarette smoke exposure and urinary 9-hydroxyfluorene levels; we plan to collect information from a larger cohort to validate correlations with exposure to secondhand smoke.

Our findings were derived from longitudinal data analysed using methods with repeated measures. The generalised mixed models and general linear mixed models were fitted to adjust for participant covariates. These models have also been used in previous studies [51]. Yuan and colleagues [15] tested three models in evaluating urinary PAH metabolite levels and platelet indices. Similarly, we used three adjusted models with time as an additional covariate and assessments using the AIC and BIC. Armstrong and Gibbs [52] also used the AIC to evaluate model fit, And Etemadi et al. [53] constructed models that contained general information, genetic information, and environmental variables with the AIC ranging from 100.07 to 160.68 . In our data, the AIC was always negative, ranging from -340.6 to -1775.5 . The BIC is mostly defined as signifying a true model and is seldom applied in this context. However, we used the $\mathrm{BIC}$ because our data were longitudinal [54] and included general linear mixed models [55]. This model-selection process has been tested in work on PAH bioaccessibility to plants [56].

To the best of our knowledge, this is the first study to use human biomarkers of PAH exposure with a longitudinal dataset and repeated measures, but some limitations should be noted. First, we only measured eight urinary PAH metabolites and not 8-hydroxy-2'-deoxyguanosine, which has been validated as a urinary marker of PAH exposure [57]. Second, the dose-response relationship is a cornerstone of the discovery process of environmental biomarkers, and the number of participants in our study is small. Thus, more subjects are needed to validate the findings in a longitudinal manner. Finally, genetic information may also be a factor in platelet indices and should be investigated.

\section{Conclusion}

Long-term exposure to low concentrations of PAHs affects platelet counts, platelet distribution width, mean platelet volume, and platelet-large cell ratio. Exposure to second-hand smoke may enhance the effect of PAHs such as fluorene on mean platelet volume.

\section{Declarations}


Ethics approval and consent to participate

The work has been approved by the China Institute for Radiation Protection (CIRP). We have added the ethic approval and the informed consent form in the end of the Supplementary materials.

\section{Consent for publication}

Not applicable

\section{Availability of data and materials}

The datasets generated and/or analysed during the current study are not publicly available due to there are several researches according to the dataset under analysis, but are available from the corresponding author on reasonable request.

\section{Competing interests}

The authors declare that they have no competing interests

\section{Funding}

The work is under the support of Key Area Environmental and Health Survey Project[21111011101EHSM].

\section{Authors' contributions}

Jing Cui, Durong Chen, Caili Zhao, Zimeng Li, Jiefang Duan: Conceptualization, Methodology, Software;

Jing Cui, Ting Zhang, Chao Zhang, Zhenwei Xue, Xiaona Kong, Yufeng Guo, Xiaoming Liu: Data curation, Writing- Original draft preparation.;

Xiaolin Zhou, Hongmei Yu:Supervision;

Jing Cui, Xiaolin Zhou, Hongmei Yu: Writing- Reviewing and Editing;

\section{Acknowledgements}

We thank Liwen Bianji, Edanz Group China (www.liwenbianji.cn/ac), for editing the English text of a draft of this manuscript.

\section{References}

1. Singh A et al (2018) PAH exposure-associated lung cancer: an updated meta-analysis. Occup Med (Lond) 68(4):255-261

2. Cao L et al (2020) Effects of environmental and lifestyle exposures on urinary levels of polycyclic aromatic hydrocarbon metabolites: A cross-sectional study of urban adults in China. Chemosphere 240:124898

3. Kamal A et al (2015) A review of PAH exposure from the combustion of biomass fuel and their less surveyed effect on the blood parameters. Environmental Science Pollution Research 22(6):4076-4098

4. Dai Y et al (2019) Alterations in platelet indices link polycyclic aromatic hydrocarbons toxicity to low-grade inflammation in preschool children. Environ Int 131:105043

5. Huo X et al (2019) Maternal urinary metabolites of PAHs and its association with adverse birth outcomes in an intensive e-waste recycling area. Environ Pollut 245:453-461

6. Yao Y et al (2019) The impact on T-regulatory cell related immune responses in rural women exposed to polycyclic aromatic hydrocarbons (PAHs) in household air pollution in Gansu, China: A pilot investigation. Environ Res 173:306-317

7. Lauer FT et al (2019) Changes in human peripheral blood mononuclear cell (HPBMC) populations and T-cell subsets associated with arsenic and polycyclic aromatic hydrocarbon exposures in a Bangladesh cohort. PLoS One 14(7):e0220451

8. Ma J et al (2019) Association between urinary polycyclic aromatic hydrocarbon metabolites and dyslipidemias in the Chinese general population: A crosssectional study. Environ Pollut 245:89-97

9. Huang X et al (2018) Urinary polycyclic aromatic hydrocarbon metabolites and adult asthma: a case-control study. Sci Rep 8(1):7658

10. Hadrup $\mathrm{N}$ et al (2019) Association between a urinary biomarker for exposure to PAH and blood level of the acute phase protein serum amyloid $\mathrm{A}$ in coke oven workers. Environ Health 18(1):81

11. Salvi S et al (1999) Acute inflammatory responses in the airways and peripheral blood after short-term exposure to diesel exhaust in healthy human volunteers. Am J Respir Crit Care Med 159(3):702-709

12. TL 0 et al., The carcinogenicity of outdoor air pollution. The Lancet, 2013

13. Brucker $\mathrm{N}$ et al (2013) Biomarkers of occupational exposure to air pollution, inflammation and oxidative damage in taxi drivers. Science of The Total Environment

14. Sochacka-Tatara E et al (2018) Urinary polycyclic aromatic hydrocarbon metabolites among 3-year-old children from Krakow. Poland Environmental Research 164:212-220 
15. Chunjie et al (2018) Dose-response relationships between polycyclic aromatic hydrocarbons exposure and platelet indices. Environmental Pollution

16. Grova $\mathrm{N}$ et al (2018) Hair analysis for the biomonitoring of polycyclic aromatic hydrocarbon exposure. TOXICOKINETICS AND METABOLISM

17. Zhang T et al (2020) Effect of PAHs on Routine Blood and Immunoglobulin Indices of Residents Living in Areas Polluted by Coking. Biomed Environ Sci 33(4):286-293

18. Samir AM et al (2019) Urinary and Genetic Biomonitoring of Polycyclic Aromatic Hydrocarbons in Egyptian Coke Oven Workers: Associations between Exposure, Effect, and Carcinogenic Risk Assessment. Int J Occup Environ Med 10(3):124-136

19. Dobraca D et al (2018) Urinary biomarkers of polycyclic aromatic hydrocarbons in pre- and peri-pubertal girls in Northern California: Predictors of exposure and temporal variability. Environ Res 165:46-54

20. Li X et al., The Dose-Response Decrease in Heart Rate Variability: Any Association with the Metabolites of Polycyclic Aromatic Hydrocarbons in Coke Oven Workers?. PLoS ONE, 2012. 7(9)

21. Yuanchao et al., The Wuhan-Zhuhai (WHZH) cohort study of environmental air particulate matter and the pathogenesis of cardiopulmonary diseases: study design, methods and baseline characteristics of the cohort. BMC Public Health, 2014

22. Yang L et al (2014) Dose-response relationship between polycyclic aromatic hydrocarbon metabolites and risk of diabetes in the general Chinese population. Environ Pollut 195(dec.):24-30

23. Yebra-Pimentel I et al., A Critical Review about the Health Risk Assessment of PAHs and Their Metabolites in Foods. Critical Reviews in Food Science Nutrition, 2013. 55(10)

24. Gliner JA et al (2002) Single-Factor Repeated-Measures Designs: Analysis Interpretation 41(8):1014-1016

25. Windmeijer FJJoE, A finite sample correction for the variance of linear efficient two-step GMM estimators. (2005) 126

26. Felipe B, Maite M, R.J.I.J.o.M S, Carlos, GLMM-based modelling of growth in juvenile Octopus maya siblings: does growth depend on initial size? 2010(7): p. 7

27. Akaike, HT.J.A.C.I.T.o. (1974) A new look at the statistical model identification 19(6):716-723

28. Schwartz G (1978) Estimating the dimension of a model. Ann Stat 6(2):31-38

29. Vrieze, Scott I (2012) Model selection and psychological theory: a discussion of the differences between the Akaike information criterion (AIC) and the Bayesian information criterion (BIC). Psychol Methods 17(2):228

30. Vieira-De-Abreu A et al (2011) Platelets: Versatile effector cells in hemostasis, inflammation, and the immune continuum. Seminars in Immunopathology 34(1):5-30

31. Chu SG et al (2010) Mean platelet volume as a predictor of cardiovascular risk: a systematic review and meta-analysis. Journal of Thrombosis Haemostasis

32. Sansanayudh $\mathrm{N}$ et al (2014) Mean platelet volume and coronary artery disease: a systematic review and meta-analysis. Int J Cardiol 175(3):433-440

33. Moghadam RH et al., Comparison of mean platelet volume levels in coronary artery ectasia and healthy people: Systematic review and meta-analysis. Blood Research, 2018. 53(4)

34. Caen JP, Levy-Toledano, Sylviane (1973) Interaction between platelets and von Willebrand factor provides a new scheme for primary haemostasis. Nature New Biology 244(135):159-160

35. Francisco, Cambronero et al (2009) Biomarkers of pathophysiology in hypertrophic cardiomyopathy: implications for clinical management and prognosis. Eur Heart J 30(2):139-151

36. Hackman AM et al (2006) Review of Therapeutics - Pharmacotherapy for Idiopathic Pulmonary Arterial Hypertension During the Past 25 Years. British Journal of Nursing

37. Ochs HD et al (1980) The Wiskott-Aldrich syndrome: studies of lymphocytes, granulocytes, and platelets. Blood 55(2):243

38. Paulette et al., Inherited giant platelet disorders. Classification and literature review. American Journal of Clinical Pathology, 2000(2): p. 176-190

39. Arslan D et al., Platelet Distribution Width and Mean Platelet Volume in Children With Pulmonary Arterial Hypertension Secondary to Congenital Heart Disease With Left-to-Right Shunt: New Indices of Severity? Pediatric Cardiology, 2013. 34(4): p. 1013-1016

40. Liang Q-C et al (2014) Mean platelet volume and platelet distribution width in vascular dementia and Alzheimer's disease. Platelets 25(6):433-438

41. Jse M (2010) Brito*, et al., Acute Cardiovascular and Inflammatory Toxicity Induced by Inhalation of Diesel and Biodiesel Exhaust Particles. Toxicol Sci 116(1):67-78

42. Tseng CY, Wang JS, Chao MW (2016) Causation by Diesel Exhaust Particles of Endothelial Dysfunctions in Cytotoxicity, Pro-inflammation, Permeability, and Apoptosis Induced by ROS Generation. Cardiovascular Toxicology

43. Nemmar A et al (2015) Emodin mitigates diesel exhaust particles-induced increase in airway resistance, inflammation and oxidative stress in mice. Respiratory Physiology Neurobiology 215:51-57

44. Dai Y et al., Alterations in platelet indices link polycyclic aromatic hydrocarbons toxicity to low-grade inflammation in preschool children. Environment international, 2019. 131

45. Ghio AJ, Carraway MS, Madden MC (2012) Composition of Air Pollution Particles and Oxidative Stress in Cells, Tissues, and Living Systems. Journal of Toxicology Environmental Health Part B 15(1):1-21

46. Ovrevik et al (2017) Triggering Mechanisms and Inflammatory Effects of Combustion Exhaust Particles with Implication for Carcinogenesis. Basic Clinical Pharmacology Toxicology 
47. Goulaouic et al (2008) Effect of polycyclic aromatic hydrocarbons and carbon black particles on pro-inflammatory cytokine secretion: impact of PAH coating onto particles. J Immunotoxicol 5(3):337-345

48. Farzan SF et al., Urinary polycyclic aromatic hydrocarbons and measures of oxidative stress, inflammation and renal function in adolescents: NHANES 2003-2008. Environmental Research, 2016. 144(JAN.PT.A): p. 149 - 57

49. Tian X et al (2017) Dose-response relationship between urinary polycyclic aromatic hydrocarbons metabolites and urinary 8-hydroxy-2'-deoxyguanosine in a Chinese general population. Chemosphere Environmental Toxicology Risk Assessment

50. Kamal A et al., Biomarkers of PAH exposure and hematologic effects in subjects exposed to combustion emission during residential (and professional) cooking practices in Pakistan. Environmental Science \& Pollution Research, 2016. 23(2): pp 1284-1299

51. lii JDC et al (2012) Exposure to polycyclic aromatic hydrocarbons and serum inflammatory markers of cardiovascular disease. Environ Res 117(none):132-137

52. Armstrong BG, Gibbs G (2009) Exposure-response relationship between lung cancer and polycyclic aromatic hydrocarbons (PAHs). Occupational Environmental Medicine

53. Etemadi A et al., Variation in PAH-related DNA adduct levels among non-smokers: The role of multiple genetic polymorphisms and nucleotide excision repair phenotype. International Journal of Cancer, 2012

54. Jones RH, Bayesian information criterion for longitudinal and clustered data. Stats in Medicine, 2011. 30(25)

55. Sanquetta CR et al., Selection criteria for linear regression models to estimate individual tree biomasses in the Atlantic Rain Forest, Brazil. Carbon Balance Management, 2018. 13(1)

56. Davin M et al., Temporal Evolution of PAHs Bioaccessibility in an Aged-Contaminated Soil during the Growth of Two Fabaceae. International journal of environmental research public health, 2020. 17(4016)

57. Zakharenko AM et al (2017) Basophil mediated pro-allergic inflammation in vehicle-emitted particles exposure. Environ Res 152:308-314

\section{Figures}

\begin{tabular}{|} 
All participants were residents for more than 25 years in a village \\
$1-2 \mathrm{~km}$ away from a coal plant but were non-occupational \\
population in PAHs polluted areas and were collected from \\
2014 to $2019 .(\mathrm{N}=418)$
\end{tabular}

Exclusion criteria for participation:
(1) The short working-experience
in the coal plant $(\mathrm{N}=9)$
(2) Less than twenty-five-year
residents' period $(\mathrm{N}=24)$
(3) The barbeque habit $(\mathrm{N}=11)$

Three-time follow-up for all paticipants. $(\mathrm{N}=374)$

\begin{tabular}{l|l} 
& Exclusion criteria for follow-up \\
(1) Loss of two follow-up records & $(\mathrm{N}=57)$ \\
(2) Loss of one annual follow-up & record (N=21) \\
(3) The urine or blood samples & were not collected on the same \\
& morning $(\mathrm{N}=74)$
\end{tabular}

Participants have finally left for further analysis

$(\mathrm{N}=222)$ 


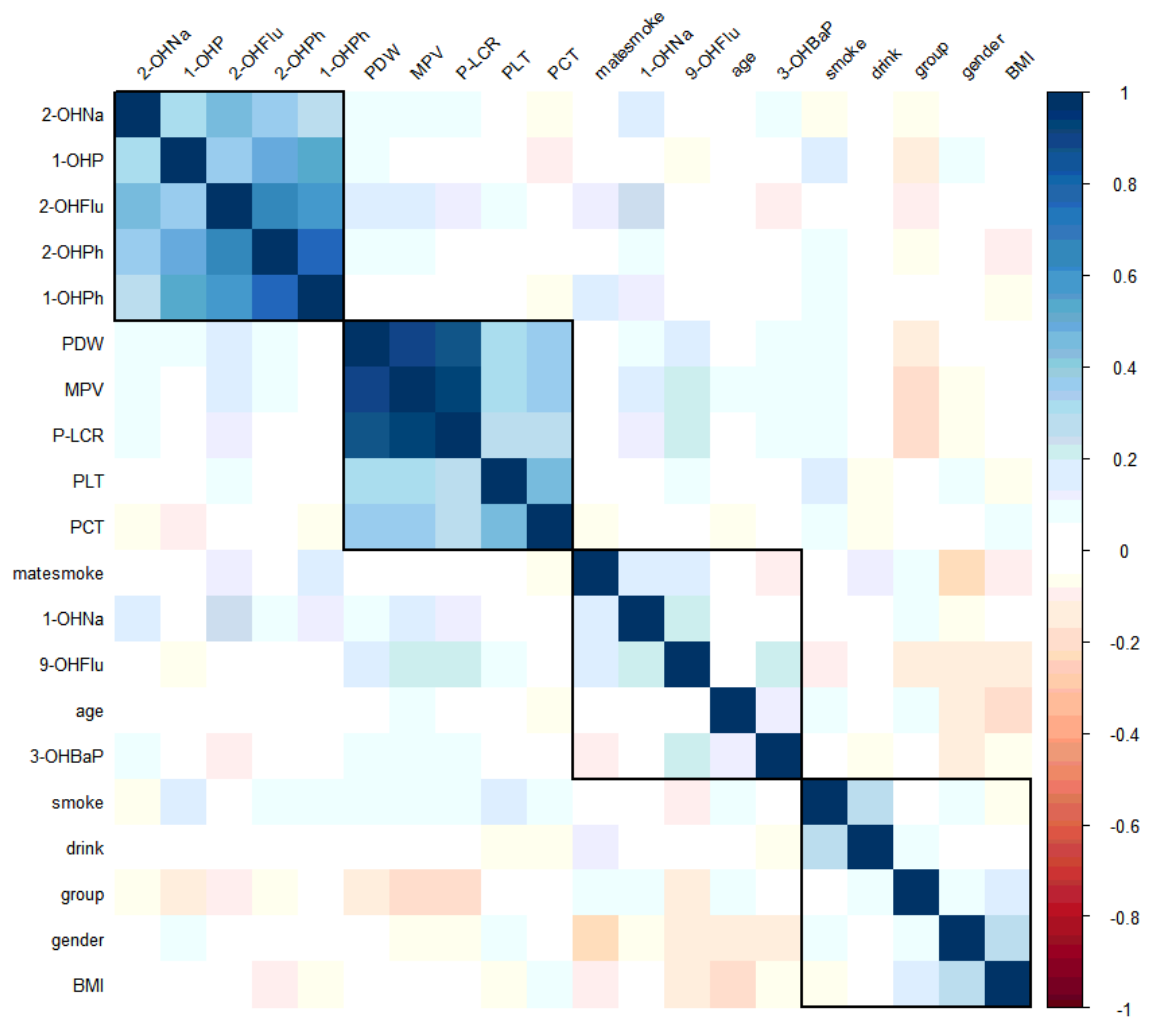

Figure 2

The correlation and cluster of all variables 


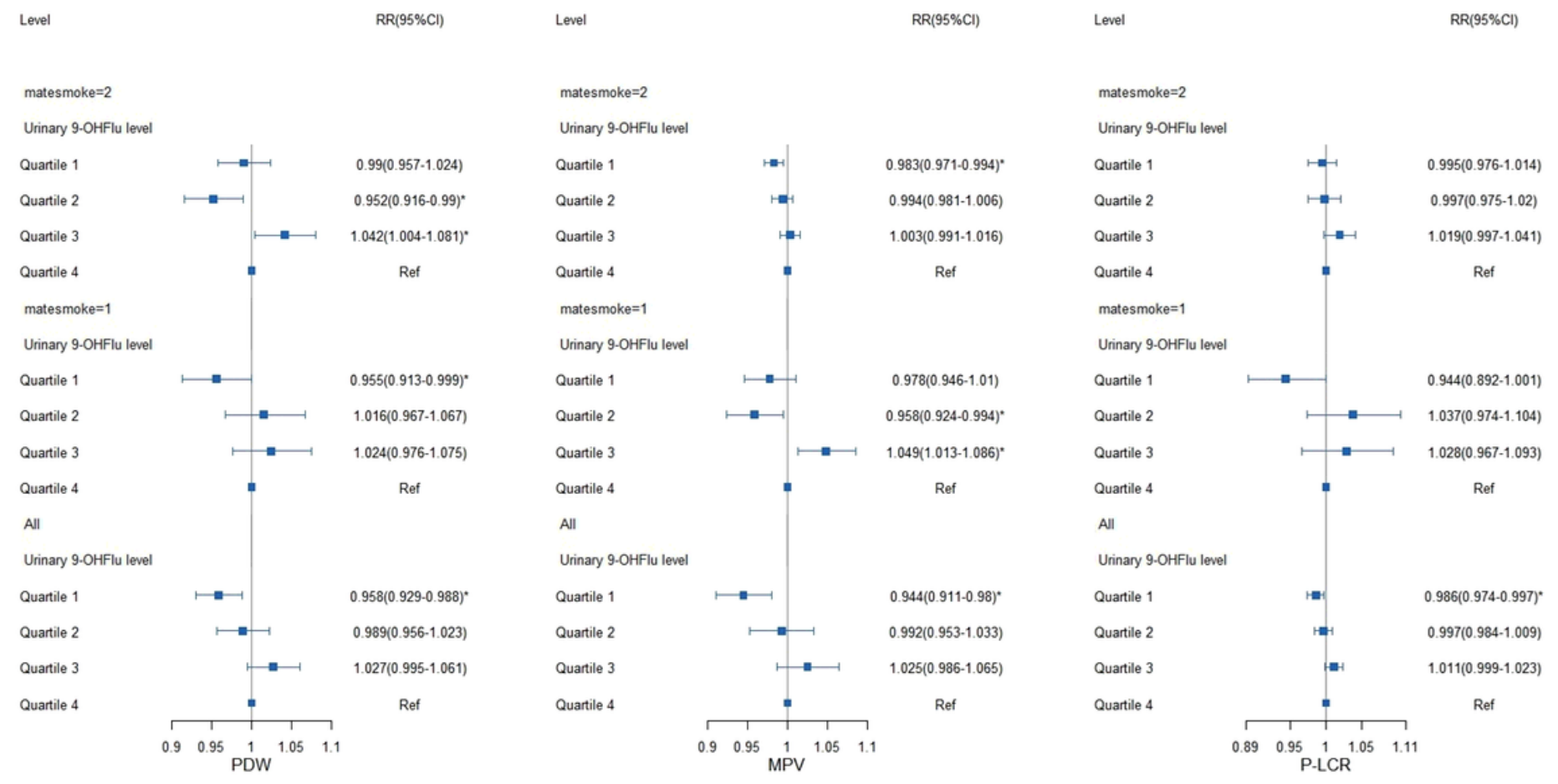

\section{Figure 3}

The dose-respond effect from 9-OHFlu and the subgroup analysis by second-hand exposure

\section{Supplementary Files}

This is a list of supplementary files associated with this preprint. Click to download.

- Supplementarymaterial.docx 